\title{
Characterizing the transport pathways of Asian dust
}

\author{
Fujung Tsai, ${ }^{1}$ George Tai-Jen Chen, ${ }^{2}$ Tsun-Hsien Liu, ${ }^{3}$ Wen-Dian Lin, ${ }^{3}$ and Jien-Yi Tu ${ }^{4}$ \\ Received 5 December 2007; revised 5 March 2008; accepted 15 May 2008; published 9 September 2008.
}

[1] Backward trajectories, synoptic analyses, and regional dust models are applied to analyze the aerosol particles obtained from aircraft measurements during major dust events in the Asian Pacific Regional Aerosol Characterization Experiment (ACE-Asia) to understand the controlling mechanism of Asian dust transport. The selected high concentrations of aerosol measurements are traced back to their source areas, and the summarized eleven representative trajectories of dust particles are categorized into three types, including the upper-level (U type), lower-level (L type), and descending (D type) transport. The characteristics of the dust transport during different stages for each of the three types are inspected. It is found that the transport distance of a dust event strongly depended on the source areas relative to the synoptic conditions. For source areas ahead of a trough, the dust particles can be uplifted into the free troposphere. If the uplifted dust particles move to the ascending areas of a trough or ascend due to other processes in the later stage, then the dust particles likely travel longer distances. When dust particles ascend in an area too close to the trough, their subsidence may be expected as sinking motion could occur after trough passage, and thus the transport distance is limited. Uplifted dust particles are typically found at a height of $400-700 \mathrm{hPa}(2-4.5 \mathrm{~km}$ above ground level) over source regions. For dust particles that are generated behind a trough, the vertical motion is limited to a layer around $700 \mathrm{hPa}$, and the transport distance is also shorter.

Citation: Tsai, F., G. T.-J. Chen, T.-H. Liu, W.-D. Lin, and J.-Y. Tu (2008), Characterizing the transport pathways of Asian dust, J. Geophys. Res., 113, D17311, doi:10.1029/2007JD009674.

\section{Introduction}

[2] Asian dust has been observed to travel over a very long range to the Pacific Ocean, Canada and the United States [Rex et al., 1969; Duce et al., 1980; Shaw, 1980; Uematsu et al., 1983; Merrill et al., 1989; Bodhaine, 1995; Husar et al., 1997, 2001; Wilkening et al., 2000; McKendry et al., 2001]. Dust generated by strong surface winds under dry conditions [Kurosaki and Mikami, 2003; Natsagdorj et al., 2003; Wang et al., 2003; Lim and Chun, 2006] can be uplifted into the free troposphere through meteorological processes and then carried by the westerlies thousands of kilometers away from the source areas. Although longrange transport occurs, dust is usually observed to deposit in the interior continent or offshore regions. For example, the Takalamakan Desert in China is not only the source but also the sink of dust particles produced locally [Sun et al.,

\footnotetext{
${ }^{1}$ Department of Marine Environmental Informatics, National Taiwan Ocean University, Keelung, Taiwan.

${ }^{2}$ Department of Atmospheric Sciences, National Taiwan University, Taipei, Taiwan

${ }^{3}$ Department of Atmospheric Sciences, National Central University, Jhungli, Taiwan.

${ }^{4}$ Department of Atmospheric Sciences, Chinese Culture University, Taipei, Taiwan.
}

Copyright 2008 by the American Geophysical Union. 0148-0227/08/2007JD009674\$09.00
2001]. Downwind areas of the Asian dust, such as the Loess Plateau, southeastern China, Korea, and Japan (Figure 1) are the main deposition regions during dust events [e.g., Iwasaka et al., 1983; Xiao et al., 1997; Chun et al., 2001; Sun et al., 2001; Zhou et al., 2002; Murayama et al., 2003; Trochkine et al., 2003; Arimoto et al., 2004; Kim et al., 2004; Park et al., 2004; Shimizu et al., 2004]. Since various ranges of dust transport are observed, many interesting questions are raised regarding the mechanisms for controlling dust transport.

[3] Transport of dust particles is regulated by meteorological conditions and the local characteristics of the source regions. For example, the observational study by Sun et al. [2001] indicated that dust from the Taklamakan and Gobi Deserts (Figure 1) experiences different transport processes. They pointed out that, in the Gobi Desert, dust particles are usually lifted to an elevation of less than $3 \mathrm{~km}$ and then deposited in the Loess Plateau, southeastern China, offshore regions, and the nearby North Pacific Ocean. On the other hand, the Taklamakan Desert is surrounded by high terrain with an averaged elevation of over $5 \mathrm{~km}$, and the relatively low area is located only to the east of the desert. Thus when the low-level easterlies prevail, dust must be uplifted to an elevation of over $5 \mathrm{~km}$ to be transported out of the source region. The elevated dust particles from the Taklamakan Desert are usually transported over long distances as suggested by Sun et al. [2001]. The presence of an elevated dust layer up to about $6 \mathrm{~km}$ was observed by lidar over source regions [Iwasaka et al., 2003], and the source of this 


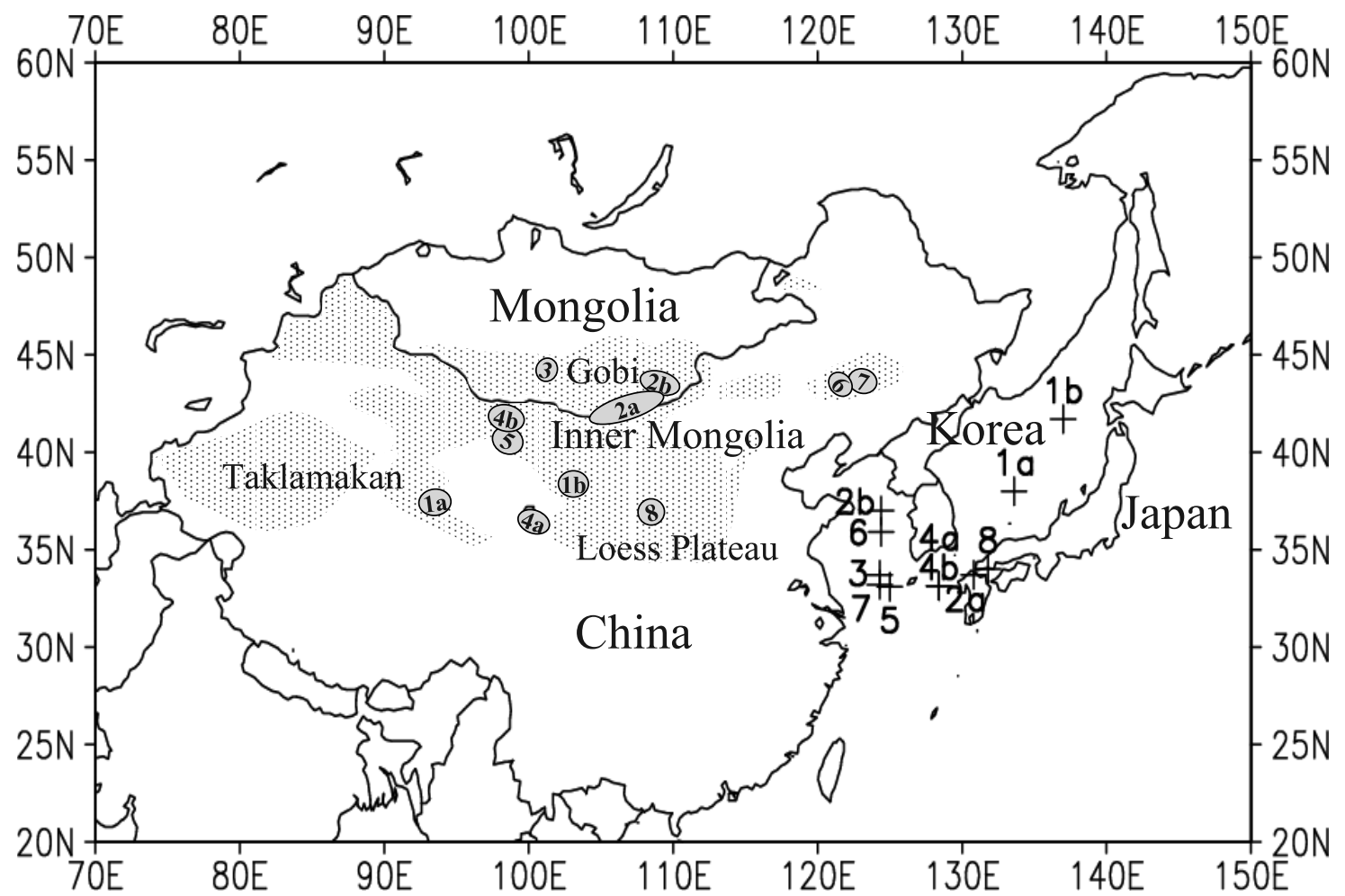

Figure 1. The TAQM modeling domain, dust sources over East Asia (dotted areas), aircraft sampling locations of the representative cases selected from eight flight measurements (cross marks with case numbers), and the corresponding dust sources (shaded areas with case numbers). Cases $4 \mathrm{a}$ and $4 \mathrm{~b}$ were sampled at almost the same location.

elevated dust layer was suggested to be the Taklamakan Desert [Iwasaka et al., 1983; Matsuki et al., 2003].

[4] Characteristics of dust transport are mainly determined by meteorological conditions. Chen and Chen [1987] analyzed the synoptic features favorable for the occurrence of dust storms. They observed that the ascending motion at $850 \mathrm{hPa}$ was favorable for high-level transport of dust particles. If descending motion occurs at $850 \mathrm{hPa}$, dust particles are usually transported in the lower troposphere and the transport distance is limited. Using mesoscale simulations, Liu et al. [2003] suggested that mechanical and convective turbulences are responsible for the dust vertical distribution from the surface to the mixed layer ahead of a front. During a frontal passage, large-scale dynamic forcing lifts dust from the mixed layer into the free troposphere. The uplifted dust can then be carried by the westerlies over long distances. Dickerson et al. [2007] also reported from aircraft measurements that the mechanism responsible for the vertical transport of dust particles is frontal uplifting, and the convection associated with frontal uplifting is usually dry in China during spring. Thus Asian dust can be uplifted to higher levels by frontal processes without being washed out, a condition favorable for longrange transport. An observational and numerical study by Wang and Fang [2006] suggested that the ascending motion ahead of a trough is responsible for the vertical transport of small dust particles (sizes less than $20 \mu \mathrm{m}$ ) to higher levels.

[5] Dust transport could also be affected by the synoptic features in the downwind areas. Mesoscale simulations of the dust event observed over British Columbia, Canada by McKendry et al. [2001] suggested that the descent of Asian dust was associated with an upper level ridge. This is similar to the results of previous studies that meteorological conditions, such as anticyclonic system can result in the sinking of dust particles along their transport path [Merrill et al., 1989; Merrill and Kim, 2004].

[6] Asian dust events are usually recognized to be associated with frontal systems [Sun et al., 2001; Liu et al., 2003; Aoki et al., 2005; Takemi and Seino, 2005; Wang and Fang, 2006]. However, the question of why, during some events and not in others, dust particles can be uplifted to the free troposphere and result in long-range transport is still not clear. In this study, the mechanisms responsible for the vertical distribution of dust and the characteristics of dust transport will be investigated. The role of fronts and troughs in regulating the vertical transport of dust particles will be discussed.

[7] Aircraft measurements obtained during major dust events in spring 2001 are used for this study. During these dust events, the Asian Pacific Regional Aerosol Characterization Experiments (ACE-Asia) was conducted off the coast of China, Japan, and Korea [Huebert et al., 2003] (Figure 1). High concentrations of aerosol particles, mainly composed of dust, were obtained both in the mixed layer and the free troposphere [Tsai et al., 2004]. Traditionally, dust measurements are taken near the surface, and thus the study of the vertical distribution of dust is often limited. The aircraft measurements conducted during ACE-Asia in spring 2001 
Table 1. Flight Numbers, Flight Periods, and the Height of the Peak Concentration of Particles for Eight Flight Measurements on Board NCAR C-130 Research Aircraft Operated During Major Dust Events in the 2001 ACE-Asia Campaign

\begin{tabular}{cccl}
\hline $\begin{array}{c}\text { Case } \\
\text { Number }\end{array}$ & $\begin{array}{c}\text { Flight } \\
\text { Number }\end{array}$ & $\begin{array}{c}\text { Flight Period (UTC) } \\
\text { (month/date hour:min) }\end{array}$ & $\begin{array}{c}\text { Height of Peak } \\
\text { Concentration }(\mathrm{km})\end{array}$ \\
\hline 1 & RF5 & $04 / 08$ 03:04-04/08 10:39 & $4.0-4.5$ \\
2 & RF6 & $04 / 1023: 15-04 / 1107: 21$ & near surface \\
3 & RF7 & $04 / 1123: 42-04 / 1209: 14$ & near surface \\
4 & RF9 & $04 / 1623: 39-04 / 1709: 28$ & $2.0-3.0$ \\
5 & RF10 & $04 / 1723: 36-04 / 1809: 03$ & boundary layer \\
6 & RF13 & $04 / 2323: 30-04 / 2409: 13$ & near surface \\
7 & RF15 & $04 / 2700: 03-04 / 2710: 11$ & near surface \\
8 & RF19 & $05 / 0322: 56-05 / 0407: 37$ & $2.0-2.5$ \\
\hline
\end{tabular}

provided a set of extremely valuable data for understanding the mechanisms of vertical transport of Asian dust.

[8] In this study, dust events with high concentrations of aerosol particles measured during ACE-Asia are traced back to their source areas, and the dust trajectories are classified into three types according to their vertical distributions. The synoptic features for different types of dust trajectories are analyzed and the dust distributions are inspected through regional dust simulations. The role of fronts and troughs in determining the vertical distribution of Asian dust, will be discussed.

\section{Data Used}

\subsection{Aerosol Particles}

[9] In spring 2001, major dust events were observed during the following periods: 5-8 April (Case 1), 814 April (Case 2 and 3), 12-18 April (Case 4 and 5), 22-27 April (Case 6 and 7), and 29 April-5 May (Case 8). During these periods, concentrations of aerosol particles greater than $100 \mu \mathrm{g} \mathrm{m}^{-3}$ were obtained by the corresponding eight flight cases on board the NCAR C-130 research aircraft. Results of Tsai et al.'s [2004] model calculations indicated that these high concentrations of aerosol particles usually consisted of more than $90 \%$ dust. Therefore the aircraft measurements from these 8 flight cases are selected in this study for dust transport analyses.

[10] Table 1 lists the flight numbers and flight periods of these eight flight cases. In Table 1, Cases 1 to 8 correspond to research flights 5, 6, 7, 9, 10,13,15 and 19 on board the NCAR C-130, respectively. The aircraft measurements were conducted off the coast of China, Japan, and Korea (Figure 1). Each flight started in the morning, according to local standard time (LST), during dust events, and lasted for 7 to 10 hours. The flight periods are converted to Coordinated Universal Times (UTC) in Table 1. Note that the LST is UTC plus 8 hours. Figure 2 shows the vertical profile of aerosol concentration obtained during the eight flight cases, with the concentrations vertically averaged every half kilometer up to $7 \mathrm{~km}$. The maximum concentrations of aerosol particles are identified either in the free troposphere or near the surface during the eight flights. Among these flights, Cases 1, 4 and 8 are the three flights in which maximum concentrations of particles are found above $2 \mathrm{~km}$ in the free troposphere. In the rest of the cases, on the other hand, the maximum concentrations are obtained near the surface layer. Case 2 is the only flight in which concentrations of particles greater than $100 \mu \mathrm{g} \mathrm{m}^{-3}$ are observed in both the free troposphere and near the surface. In Cases 1 and 2, dust particles are also observed to transport over the Pacific Ocean and reached North America (TOMS at http:// toms.gsfc.nasa.gov/aerosols/aerosols.html). The heights of the peak particle concentrations for the eight flight cases are summarized in Table 1.

[11] Because the aerosol mass was not directly measured on board the NCAR C-130, the University of Washington's light scattering measurements operated aboard the aircraft are used to derive the mass of aerosol particles presented in Figure 2. The light scattering measurements of the aerosols were taken from integrating nephelometers at $550 \mathrm{~nm}$ and low relative humidity. Data were collected between 0.2 and 2 seconds resolutions and then processed at a 1-minute resolution. Aerosol particles, includes both coarse and fine modes based on a cutoff point in aerodynamic diameter of $1 \mu \mathrm{m}$, were measured and their masses were summed as the total aerosol mass. The mass scattering efficiencies and uncertainties used for coarse and fine particles were $0.8 \pm$ 0.4 and $3 \pm 1 \mathrm{~m}^{2} \mathrm{~g}^{-1}$, respectively. These were derived from concurrent measurements of the aerosol light-scattering coefficient and some estimates of particle mass [Andreae et al., 2002]. The mass of aerosol particles derived from the above light scattering formulas has a $30-50 \%$ uncertainty due to uncertainties in the mass scattering efficiencies. More detailed descriptions of the data can be found from the works of Masonis et al. [2002] and Anderson et al. [2003].

[12] Since light scattering measurements were processed at 1-minute resolution, more than 2000 measurements were obtained during each of the eight flights, and mass concentration of aerosol particles was derived. When the derived mass concentration of aerosol particles is greater than $100 \mu \mathrm{g} \mathrm{m}^{-3}$, the data is selected for trajectory analyses. A total of about 1600 aircraft measurements are selected under this criterion.

\subsection{Meteorological Data}

[13] Gridded reanalysis data from the National Centers for Environmental Prediction (NCEP) [Kalnay et al., 1996; Kistler et al., 2001] were used for analyzing the synoptic conditions during dust events. The global reanalysis data applied in this study has a spatial resolution of $2.5^{\circ} \times 2.5^{\circ}$, a time resolution of 6 hours $(0000,0600,1200,1800$ UTC), and includes geopotential height, air temperature, vertical velocity (omega), and wind field at 950, 850, 700, 500, and $300 \mathrm{hPa}$ and sea level pressure. Dust observations at surface stations from the World Meteorological Organization (WMO) are also used to identify dust events. In the WMO SYNOP code, the 3-hourly present weather reports with codes from 6 to 9 for distinguishing haze and smoke intensity and 30 to 35 for distinguishing severe dust storm are employed to identify dust events in this study.

\section{Model Descriptions}

\subsection{Backward Trajectory Model}

[14] The NOAA Hybrid Single-Particle Lagrangian Integrated Trajectory (HYSPLIT) model [Draxler and Hess, 1997] is used to calculate three-dimensional backward 

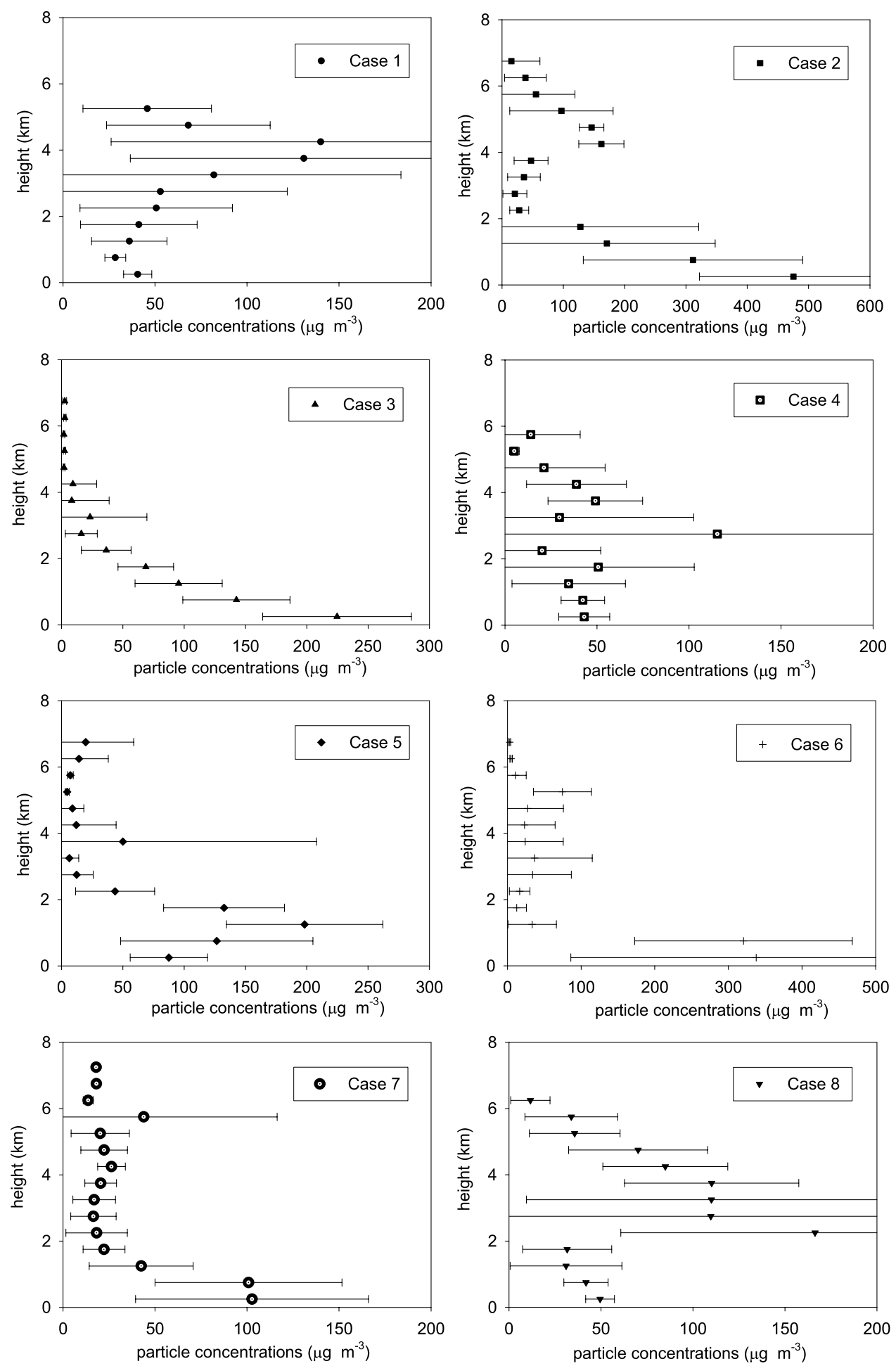

Figure 2. Vertical aerosol concentrations from eight flight measurements on board NCAR C-130 research flights operated during major dust events in the 2001 ACE-Asia campaign. The concentrations are vertically averaged by every $0.5 \mathrm{~km}$ with standard deviations (horizontal lines).

trajectories of the dust particles obtained during major dust events. The updated model (version 4) is applied to compute particle trajectories with a horizontal resolution of $1^{\circ} \times 1^{\circ}$. The vertical resolution of the trajectory model depends on the wind field. The wind fields for the trajectory calculations are obtained from the final run of a series of NCEP operational model runs (FNL), with 13 levels above the surface layer. These model runs assimilate all available observations to produce dynamically consistent 6-hourly analyses and short-range forecasts, and are known as the global data assimilation system [Derber et al., 1991; Kanamitsu, 1989; Parrish and Derber, 1992; Petersen 
and Stackpole, 1989]. Vertical velocities are obtained from the continuity equation at each model surfaces and then vertically interpolated to the sigma coordinate system in the trajectory model. There are several possible sources of uncertainties in the trajectory calculations, including the lowresolution meteorological data and subgrid scale vertical motion. To minimize the uncertainties, model-diagnosed vertical velocities from the continuity equation are used, as suggested by previous studies [Fuelberg et al., 1996; Stohl, 1998].

\subsection{Regional Dust Model}

[15] The dust module in the Taiwan Air Quality Model (TAQM-Dust) [Tsai et al., 2004] is developed to simulate regional dust distributions over Asia. The three-dimensional TAQM is a regional model used to simulate the timevarying three-dimensional distribution of trace gases and particles [Jeng et al., 2000]. The dust modeling domain for this study covers East Asia within $20^{\circ} \mathrm{N}$ to $60^{\circ} \mathrm{N}, 70^{\circ} \mathrm{E}$ to $150^{\circ} \mathrm{E}$ (Figure 1), with a model horizontal resolution of $81 \mathrm{~km} \times 81 \mathrm{~km}$, and a time step of 5 minutes. The model domain is reasonably large enough to cover all of the dust sources in China, and no other dust source from beyond the boundaries was input to the domain. Vertically, the model is divided into 15 layers using sigma coordinates, with depths of approximately $40 \mathrm{~m}$ near the surface and $1-2 \mathrm{~km}$ near the tropopause.

[16] Hourly meteorological data input to the regional dust model, for quantifying transport and diffusion of mineral dust, is obtained from NCAR/Penn State Mesoscale Meteorological Model (MM5) [Grell et al., 1995] simulations. The updated mesoscale model is a nonhydrostatic, terrainfollowing sigma-coordinate model. The meteorological model domain is slightly larger than the dust model domain shown in Figure 1. The horizontal resolution of the MM5 model domain is the same as in the dust model, so the meteorological data output from the model can be directly used by the dust model. Vertically, MM5 is divided into 24 layers, but only 15 layers of them are selected as input to the dust model. A 3-minute time step is used for model integration. Initial and boundary conditions for MM5 are obtained from the NCEP reanalysis data set. Boundary conditions are updated at 6-hour intervals during model integration. Higher-order (16-point) interpolation in horizontal and both linear in pressure (for U, V winds, and relative humidity) or log pressure (geopotential height and temperature) interpolations in vertical are used for interpolating NCEP reanalysis data into MM5 model grid. Both higher spatial resolution data from NCEP AVN model and lower resolution data from ECWMF Reanalysis and NCEP Reanalysis models have been used for initial and boundary conditions in MM5 for simulating dust concentrations. It was found that the results were not sensitive to the spatial resolution of the meteorological fields. Also, the NCEP reanalysis data set can be freely accessed from the Website (http://www.cdc.noaa.gov/index.html). Thus it was used instead of using higher resolution models in this study.

[17] A dust module which includes the emissions, transport, and depositions of dust, has been incorporated into the TAQM for this study. The emission module of dust is developed based on the work of Wang et al. [2000]. In that study, the onset of the dust emission is controlled by three factors: frictional velocity, surface humidity, and predominant weather conditions. When all three factors satisfy the prescribed thresholds, the emission intensity is calculated using the following equation (1).

$$
\mathrm{S}=\mathrm{C}_{1} \mathrm{C}_{2} \mathrm{u}_{*}^{2}(1-\mathrm{RH}) \mathrm{W}
$$

[18] In equation (1), $\mathrm{S}$ is the dust emission intensity in $\mathrm{kg}$ $\mathrm{m}^{-2} \mathrm{~s}^{-1}, \mathrm{C}_{1}$ is the weighting factor of different surface conditions, $\mathrm{C}_{2}$ is an empirical factor and is determined to be $2.9 \times 10^{-11}, \mathrm{u} *$ is the friction velocity in the surface layer in $\mathrm{m} \mathrm{s}^{-1}, \mathrm{RH}$ is the surface relative humidity, and $\mathrm{W}$ is the mass weighting factor for each aerosol bin derived from the observed bin distribution over the source areas. The dust particles were divided into 12 size bins ranging from 0.13 to $20.13 \mu \mathrm{m}$. The original dust module was on a $1^{\circ} \times 1^{\circ}$ horizontal resolution, but was interpolated to the current model grid.

[19] The transport of dust is computed using a positive definite and mass conservative scheme derived by Bott [1989]. The fourth-order finite difference advection scheme is applied to minimize the problem of numerical diffusion. In addition to vertical advection and diffusion, the Asymmetrical Convective Model obtained from Pleim and Chang [1992] is applied in TAQM. Through this effective vertical mixing scheme, the emitted species are rapidly transported upward through the troposphere under convective conditions.

[20] A one-dimensional diagnostic cloud module is used to calculate subgrid-scale convective redistribution and wet removal of dust particles. Wet removal of dust particle is a difficult process to simulate, because the hygroscopic properties of mineral dust are not well known. If a dust particle gets coated with water-soluble organics or sulfate, it may be activated as cloud droplets [Fan et al., 2004], then the wet removal of dust particles involves cloud and aerosol microphysics. Due to the complexity and uncertainty of these processes, this model simplifies the wet processes by assuming that dust particles are nonhygroscopic [Carrico et al., 2003; Perry et al., 2004] and the only wet removal process considered is subcloud precipitation. The removal rate is calculated using the following equation (2) [Pruppacher and Klett, 1978].

$$
\Lambda=10.8 \mathrm{E} \mathrm{R}^{0.16} / \mathrm{D}
$$

[21] In equation (2), $\mathrm{E}$ is the coagulation kernel, and is set to be $0.83, \mathrm{R}$ is the precipitation intensity in $\mathrm{mm} \mathrm{hr}^{-1}$, and $\mathrm{D}$ is the thickness between the cloud base and top of the boundary layer, with a minimum value of $500 \mathrm{~m}$.

[22] Dust removal by dry deposition is calculated using the dry deposition velocity, derived from the aerodynamic, sublayer and canopy resistance. The dry deposition fluxes are calculated from deposition velocities and the dust concentration in the model surface layer. In addition to dry deposition in the surface layer, gravitational settling of dust particle above the surface layer is also included in the removal processes.

[23] During dust events, dust particles can have a residence time of more than a week in the model domain. Therefore a 10-day spin-up run of the model is performed 
ahead of the selected simulation period in order to produce reasonable initial conditions. After the spin-up run, the numerical simulation of the selected period is performed from 4 April to 4 May 2001 to cover the period of flight measurements.

\section{Classification of Trajectories}

[24] The selected aerosol particles from aircraft measurements during major dust events of spring 2001 are used for trajectory analysis. As discussed previously, these aerosol particles are mainly composed of mineral dust, and thus the obtained trajectories are used for analyzing dust transport. The origins of the backward trajectories are from the flight paths where selected aerosol particles are detected, and the air parcels are traced back up to a period of 6 days.

[25] Due to spatial and temporal resolution limit of the trajectory model, the trajectory was not plotted for all the 1600 aircraft measurements which were sampled at 1-minute intervals. The measurements that were traced back in fact represent samples in certain volume of air undistinguishable by trajectory resolution. The volume of air consists of a sampling distance within $0.3^{\circ}$ in latitude or longitude, a sampling height shorter than $300 \mathrm{~m}$, and a sampling time less than 20 minutes. Within the spatial and temporal variations of the flight measurements (see Table 1 and Figure 1) only one to three trajectories with different source regions and different time (at least 12 hours difference) could be found from tracing back the same flight. For some trajectories with multiple dust observations along the trajectory, the regional dust simulation is used to identify the major sources regions. The backward trajectories that did not pass through deserts at the time of dust generation are disregarded. It is possible that the source regions of these dust particles are not found due to the limitation of horizontal resolution in the trajectory model or aerosol particles originating from different sources other than dust. As a result, there were 11 trajectories being constructed from the traced samples of the 8 flight measurements.

[26] The eleven representative trajectories are then categorized into three main types according to the altitude of the trajectories, including upper-level type (U type), lower-level type (L type), and descending type (D type) Figure 3. Dust particles of the $U$ type trajectory are transported above 700 $\mathrm{hPa}$, the $\mathrm{L}$ type are transported below $700 \mathrm{hPa}$, and the Descending (D) type from above $700 \mathrm{hPa}$ to near or below $700 \mathrm{hPa}$.

[27] Generally, Asian dust is generated from high terrain in China, and thus the dust trajectories of the three types originate from a level where the surface pressure can be as low as $600-700 \mathrm{hPa}$. For the $\mathrm{U}$ and $\mathrm{D}$ type dust trajectories, the dust particles can reach the middle troposphere through ascending motion, although a quick descending motion characterizes the D type trajectory. As discussed in the introduction, many meteorological conditions, as well as particle sedimentation, could result in a slow descent of dust particles during their long-range transport. Instead of considering these slow processes, the trajectories are characterized as the descending type if they exhibit the immediate sinking movement of dust particles right after they are uplifted. For the $\mathrm{L}$ type trajectories, a maximum height around $700 \mathrm{hPa}$ is identified.

[28] In addition to the three types of trajectories discussed above, three stages of dust trajectory, including initial, ascending and downwind transport stages, are also defined in order to better analyze the processes of dust transport from sources to downwind areas. Figure 3 also shows the three stages in the dust trajectories. The initial stage represents a period when dust is generated from the source region. The source regions along the backward trajectories of dust particles are determined based on the following criteria.

[29] 1. Source regions are limited to deserts in China.

[30] 2. Surface dust observations are obtained from the source regions during dust generation.

[31] 3. Ascending motion is also found in the source regions during dust generation if the dust parcels belong to uplifted (U and D) types.

[32] In this study, the initial stage of an event is defined by the first three hours before a dust event is observed by surface stations, while the dust particles are still near the surface. The area where dust particles are generated, from the beginning to the end of the initial stage, determines the range of the source regions shown in Figure 1.

[33] The initial stage is followed by the ascending and downwind transport stages, when a dust parcel is uplifted from the surface and then transported downwind. For the U and $\mathrm{D}$ type trajectories, the ascending period is identified by ascending motion in the trajectories and concludes when the trajectories reached their maximum height (Figure 3). After that, the dust parcel is transported downwind, thus entering the downwind transport stage. For the L type trajectories, there is usually no obvious ascending period. Dust of this type is transported from surface to the mixed layer by strong surface winds during the initial stage and then moved downwind.

[34] Table 2 lists the eleven representative trajectories and their cases. The trajectory types, aircraft sampling time, locations, ambient pressure, and the derived mass concentration of aerosol particles are also listed. There are 3, 4, and 4 cases for the upper-level, lower-level, and descending types of trajectories, respectively. The case numbers listed in Table 2 are the same as those listed in Table 1, except for Cases 1, 2 and 4, in which two different trajectories are found during the same flight, and thus "a" and "b" are added to the case numbers to distinguish between the trajectories. The dust parcels of the 11 representative trajectories were sampled within their corresponding flight periods listed in Table 1 and their sampling sites are shown in Figure 1. In these representative cases, the observed heights are $500-700 \mathrm{hPa}$ for the U type, below $900 \mathrm{hPa}$ for the L type, and around 700-900 $\mathrm{hPa}$ for the D type. Case 1a is observed at around $700 \mathrm{hPa}$ and is classified as D type since the quick descending pattern of its trajectory is similar to those in the descending type. The obtained concentrations of total particles all exceed $100 \mu \mathrm{g} \mathrm{m}^{-3}$, with extremely high concentrations approaching $700 \mu \mathrm{g}$ $\mathrm{m}^{-3}$ in some cases of the $\mathrm{L}$ type. The initial time and source areas of dust generation for these representative trajectories are identified through backward trajectory analyses and are presented in Table 2 and Figure 1. Dust particles observed by the aircraft measurements originated mainly over the 


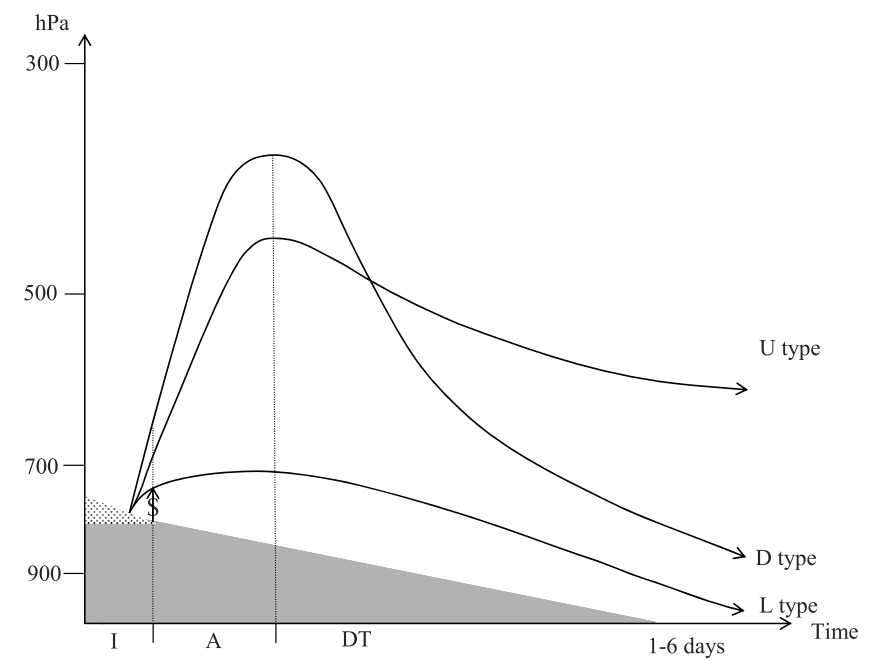

Figure 3. Schematic diagram of dust trajectories for the upper-level (U type), lower-level (L type), and descending (D type) transport of dust in the pressure-time coordinate. The topography is represented by the shaded area, and dust observations from a surface station in the desert (dot area) is marked with \$. The initial (I), ascending (A), and downwind transport (DT) stages in the trajectories are also marked.

Gobi Desert, Inner Mongolia in northern China, Loess Plateau, western China and northeastern China (Figure 1 and Table 2).

[35] Figure 4 shows the trajectories and their vertical profiles for the 3 cases of the $U$ type. All cases suggest that dusts originates from Mongolia or Inner Mongolia in northern China (Cases 1b, 2a, and 8), passing through eastern China and moving out of the coast. Dust particles in Cases 1b, 2a, and 8 originate from levels of about $550 \mathrm{hPa}, 370 \mathrm{hPa}$, and $770 \mathrm{hPa}$, respectively. Ideally speaking, dust particles should originate from the surface rather than from the levels above ground. However, the strong vertical mixing during dust generation prohibits the air parcel from being identified in the backward trajectory at the surface. Thus the dust trajectories in these cases and also the following cases are identified to originate from higher levels (e.g., $550 \mathrm{hPa}, 370 \mathrm{hPa}$, and $770 \mathrm{hPa}$ in Cases $1 \mathrm{~b}, 2 \mathrm{a}$, and 8 , respectively) rather than from ground. This is consistent with the results of previous studies [Hannan et al., 2003; Dickerson et al., 2007] that pollutants and aerosol particles could reach around $400-600 \mathrm{hPa}$ or $4 \mathrm{~km}$ during strong vertical mixing. Figure 4 shows that dust particles remain ascended in the free troposphere after the initial stage until reaching around $300-600 \mathrm{hPa}$. After that, the trajectories descend first and then ascend again. Due to the lower terrain in the downwind areas, their height above ground may increase with time.

[36] Figure 5 presents the four L-type cases which originate from deserts in Gobi (Cases $2 b$ and 3 ) and Northeast China (Cases 6 and 7 in Horqin Desert), and moved southeastward near the surface layer. For most of the cases, sinking motion is observed in the trajectories during downwind transport, although slight ascent may occur.

[37] Figure 6 shows that the source areas for the D type are located over the southern Gobi Desert in Inner Mongolia (Cases 4b and 5), the Loess Plateau (Case 4a) and western China (Case 1a in Qaidam Desert). Same as in U and L types, it also shows that the source areas can be in any deserts over China, although it is likely that the source areas in $U$ and $D$ types are to the south of those in L type. D type trajectories suggest that the dust parcel are uplifted first to layers around $400-500 \mathrm{hPa}$, although the ascent is not well identified by the trajectories model, as discussed previously. After ascent, the dust parcel then quickly descend eastward and southeastward toward the eastern coast of China, with descending rate of 170 to $240 \mathrm{hPa}$ day $^{-1}$ during the earlier downwind transport stage.

\section{Synoptic Characteristics of Three Types}

\subsection{U Type: Case $1 \mathrm{~b}$}

[38] A typical case from each of the three types of dust trajectories is selected and discussed. Within the $U$ type category of dust transport, Cases $1 \mathrm{~b}, 2 \mathrm{a}$, and 8 differ in terms of the ascending mechanism for the upward transport of dust. Case $1 \mathrm{~b}$ is selected for discussion since the ascending mechanism in Cases $2 \mathrm{a}$ and 8 is similar to that in Case 5 of the D type, and will be discussed later. The synoptic situation for Case $1 \mathrm{~b}$ starts with a $500 \mathrm{hPa}$ trough moving into the western border of China on 5 April 2001 (not shown). One day later, the trough system moves into the eastern Mongolia. Figure 7a shows that a surface low

Table 2. Aircraft Sampling Time, Location, Height Above Mean Sea Level, Concentration of Aerosol Particles, Time of Dust Generation, and the Source Areas Identified by Trajectory Analyses for the Representative Cases of the Three Different Types of Dust Transport

\begin{tabular}{|c|c|c|c|c|c|c|c|}
\hline Type & $\begin{array}{c}\text { Case } \\
\text { Number }\end{array}$ & $\begin{array}{l}\text { Sampling } \\
\text { Time }\end{array}$ & $\begin{array}{c}\text { Sampling } \\
\text { Location }\left({ }^{\circ} \mathrm{N},{ }^{\circ} \mathrm{E}\right)\end{array}$ & $\begin{array}{c}\text { Pressure } \\
(\mathrm{hPa})\end{array}$ & $\begin{array}{c}\text { Concentration } \\
\left(\mu \mathrm{g} / \mathrm{m}^{3}\right)\end{array}$ & $\begin{array}{c}\text { Time of Dust } \\
\text { Generation }\end{array}$ & $\begin{array}{c}\text { Source Areas } \\
\left({ }^{\circ} \mathrm{N},{ }^{\circ} \mathrm{E}\right)\end{array}$ \\
\hline \multirow[t]{3}{*}{$\mathrm{U}$} & $1 b$ & 08 UTC Apr 8 & $(41.7,137.0)$ & 618 & 208 & 07-10 UTC Apr 6 & $(38.4,102.3)-(38.5,104.2)$ \\
\hline & $2 \mathrm{a}$ & 00 UTC Apr 11 & $(33.7,130.8)$ & 517 & 164 & 09-12 UTC Apr 8 & $(41.3,104.1)-(43.1,109.4)$ \\
\hline & 8 & 07 UTC May 4 & $(34.0,131.8)$ & 694 & 297 & 03-06 UTC May 1 & $(37.2,108.4)-(37.6,109.4)$ \\
\hline \multirow[t]{4}{*}{$\mathrm{L}$} & $2 b$ & 03 UTC Apr 11 & $(37.0,124.4)$ & 992 & 765 & 09-12 UTC Apr 9 & $(43.7,107.8)-(43.2,110.4)$ \\
\hline & 3 & 05 UTC Apr 12 & $(33.7,124.3)$ & 944 & 242 & 12-15 UTC Apr 9 & $(44.2,101.0)-(43.9,101.8)$ \\
\hline & 6 & 05 UTC Apr 24 & $(35.9,124.4)$ & 936 & 456 & 04-07 UTC Apr 23 & $(43.9,120.7)-(42.6,122.0)$ \\
\hline & 7 & 04 UTC Apr 27 & $(33.2,124.3)$ & 979 & 117 & 23 UTC Apr 22-02 UTC Apr 23 & $(43.9,121.9)-(42.9,124.0)$ \\
\hline \multirow[t]{4}{*}{$\mathrm{D}$} & $1 \mathrm{a}$ & 04 UTC Apr 8 & $(38.0,133.6)$ & 693 & 140 & 11-14 UTC Apr 4 & $(37.2,92.6)-(37.4,94.4)$ \\
\hline & $4 a$ & 08 UTC Apr 17 & $(33.1,128.4)$ & 750 & 291 & 8-11 UTC Apr 13 & $(36.9,99.0)-(36.4,100.9)$ \\
\hline & $4 b$ & 08 UTC Apr 17 & $(33.1,128.4)$ & 843 & 120 & 15-18 UTC Apr 12 & $(41.9,97.2)-(41.0,99.6)$ \\
\hline & 5 & 05 UTC Apr 18 & $(33.1,125.0)$ & 902 & 245 & 05-08 UTC Apr 13 & $(41.0,97.8)-(40.1,99.6)$ \\
\hline
\end{tabular}




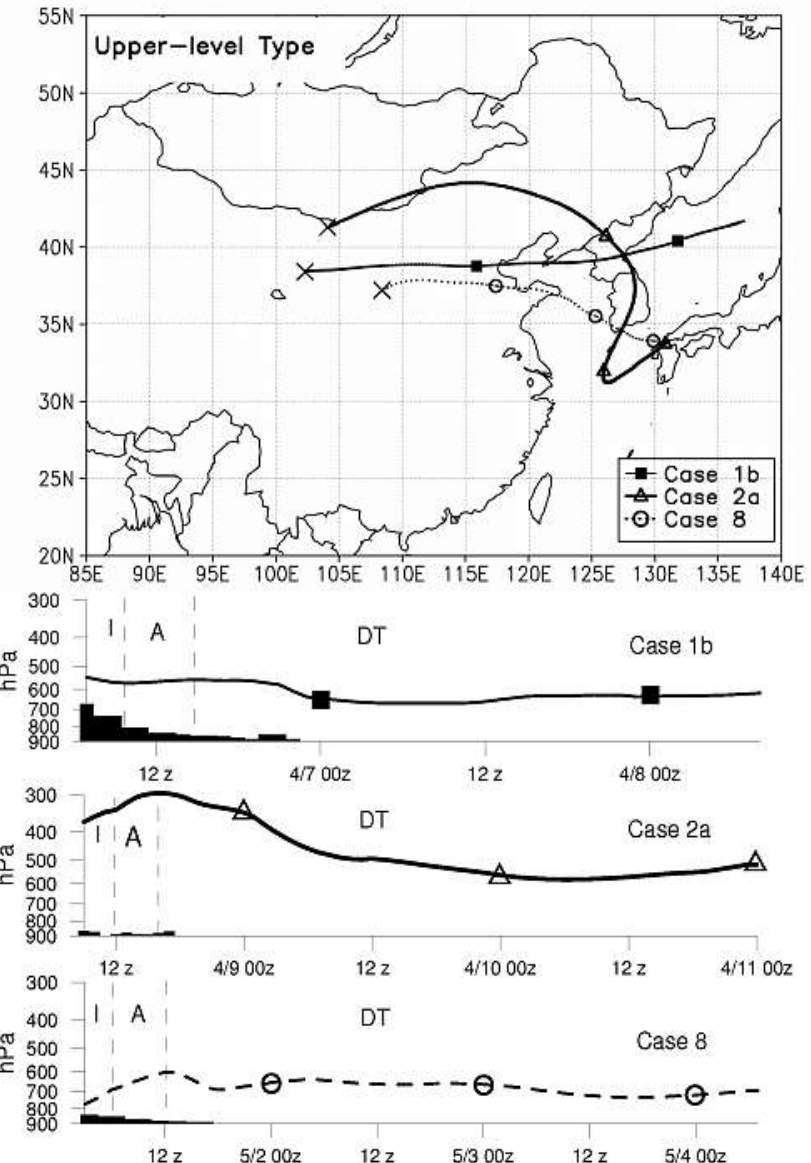

Figure 4. Backward trajectories and their vertical profiles for the three cases of $U$ type. The source areas are marked by crosses, and trajectories are labeled by different symbols at 24-hour intervals. The initial (I), ascending (A), and downwind transport (DT) stages for each trajectory are also indicated (see text for details). The black shaded area indicates the terrain.

( $\mathrm{L}$ in the figure) is located in eastern Mongolia and the surface frontal system extends from the low center southward into central China at 06 UTC on 6 April. Case $1 \mathrm{~b}$ is characterized by an intense surface low $(\mathrm{L}=987 \mathrm{hPa})$ together with a weak surface high $(\mathrm{H}=1026 \mathrm{hPa})$. Due to the existence of the cyclonic system, the associated strong pressure gradient results in strong surface wind over the Gobi Desert, leading to the dust generation over the area (see $\$$ on the map). Figure 7a shows that the dust parcels in Case $1 \mathrm{~b}$ (see circle with $\mathrm{x}$ ) are located over the southern Gobi Desert in Inner Mongolia, slightly behind the surface front. The wind speed, temperature, and dew point temperature obtained from the surface stations surrounding the dust parcels are $8 \mathrm{~m} \mathrm{~s}^{-1}, 13^{\circ} \mathrm{C}$ and $-7^{\circ} \mathrm{C}$, respectively (not shown), indicating a dry and windy conditions for dust generation.

[39] Figure $7 \mathrm{~b}$ shows the ascending stage when the dust parcel in Case $1 \mathrm{~b}$ is uplifted to the southwest of the $500 \mathrm{hPa}$ trough over the Inner Mongolia Desert, where upward motion prevails at 12 UTC on April 6. The strong surface wind (see Figure 7a) passing over Mt. Qilian to the south of the dust parcel results in the ascending motion. Thus the dust parcel is uplifted from the desert surface to $500 \mathrm{hPa}$ due to the terrain effect. While the dust parcel is located to the southwest of the trough, it travels with the $500 \mathrm{hPa}$ zonal wind for several hours during this stage. The regional dust simulation at this level also shows the uplifted dust clouds over the ascending region around the dust parcel (Figure 7b). Note that the dust parcel identified by the backward trajectory is located at $560 \mathrm{hPa}$ rather close to $500 \mathrm{hPa}$. Likewise, the synoptic maps for the closest pressure level are analyzed for the dust parcel in the following sections.

[40] After 6 hours of ascending, the dust parcel enters the downwind transport stage (Figure 4). Figure 7c shows that the dust parcel has descended to $600 \mathrm{hPa}$ on April 7. A cutoff low $\left(50^{\circ} \mathrm{N}, 120^{\circ} \mathrm{E}\right)$ and the associated trough form over Northeast China at this time. The dust parcel located to the southeast of the trough follows the zonal flow and slightly ascends again in the later stage due to the upward motion in the low. On April 8, an aerosol concentration greater than $200 \mu \mathrm{g} \mathrm{m}^{-3}$ is measured at about $4 \mathrm{~km}$ off the eastern coast of Asia. The $U$ type trajectories show that the condition most favorable for long-range transport is to

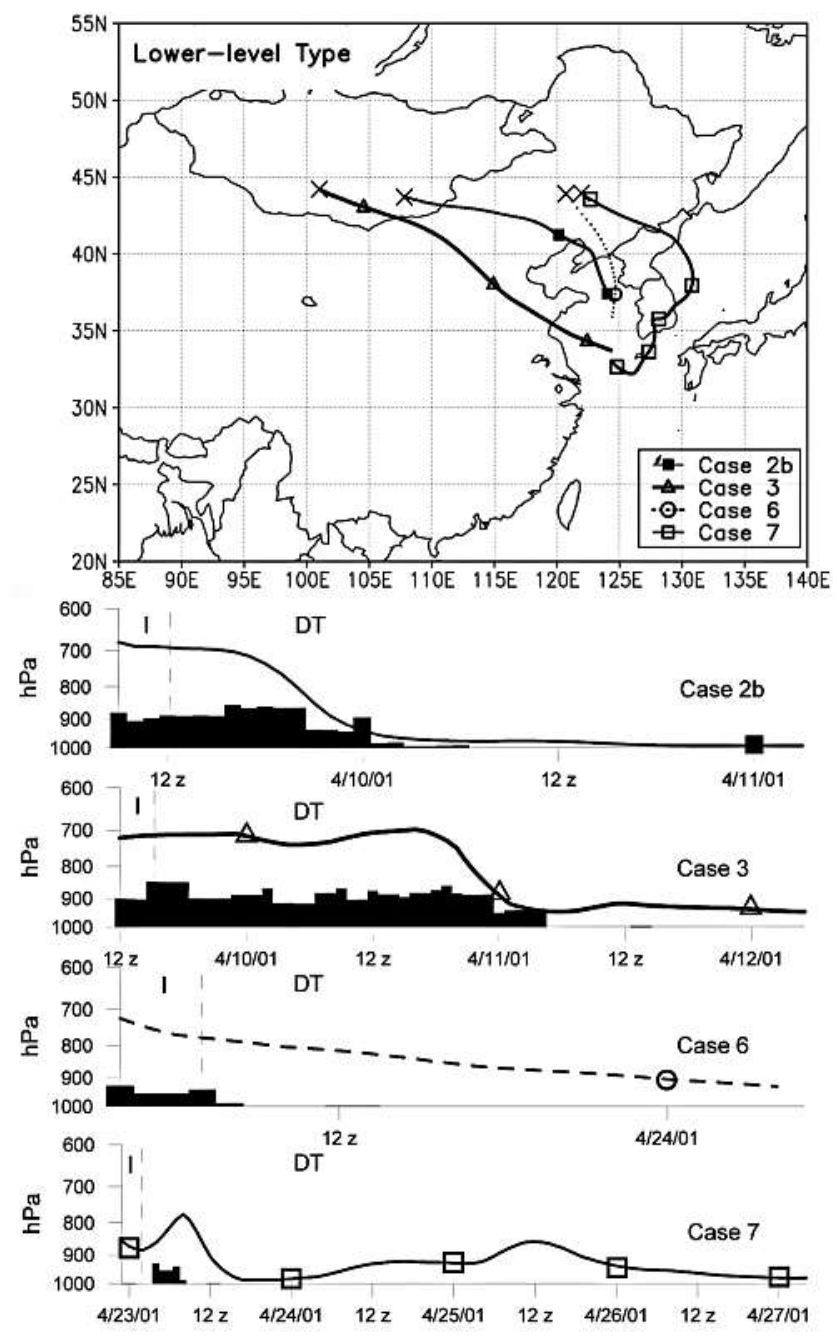

Figure 5. As in Figure 4, but for the four cases of the L type. 


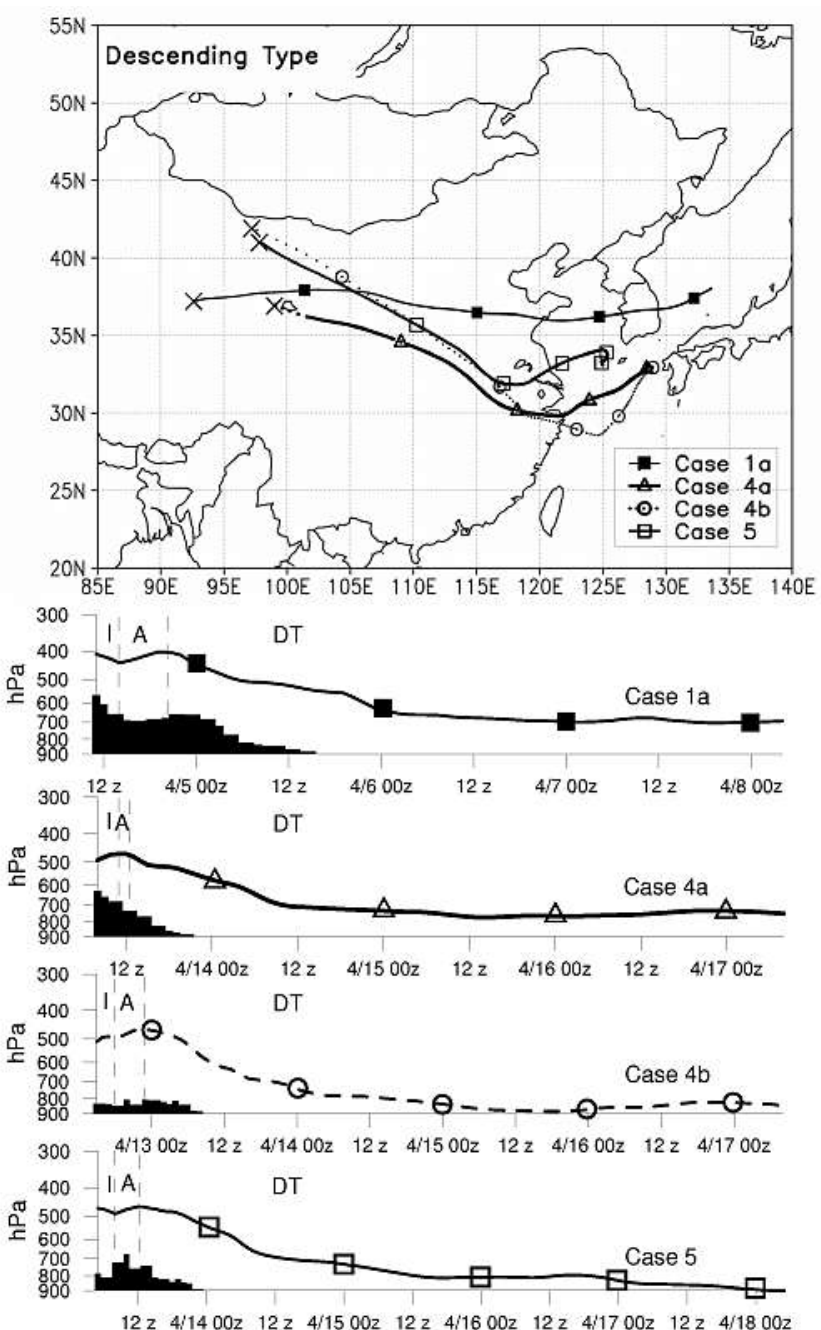

Figure 6. As in Figure 4, but for the four cases of the D type.

remain at a relatively high altitude where the winds are typically strongest, and no major descending motion occurs. As a result, dust parcel can remain in the free troposphere over a long distance.

[41] Figure 7d shows the east-west vertical cross section of the streamlines and the calculated dust concentration along $38^{\circ} \mathrm{N}$ ( $\mathrm{AB}$ line in Figure $7 \mathrm{~b}$ ) where the traced dust parcel is located at 12 UTC on April 6. It shows that the dust parcel is uplifted to about $560 \mathrm{hPa}$, while the vertical extent of dust clouds reaches a maximum height of about $300 \mathrm{hPa}$ where upward motion prevails. This is consistent with the uplift of dust parcel due to the terrain effect discussed previously.

\subsection{Type: Case $2 b$}

[42] In contrast to the $U$ type, dust parcels of the $L$ type travel within the lower troposphere. Case $2 b$ of this type is a typical case and is selected for discussion.

[43] The dust event of Case $2 \mathrm{~b}$ occurs as a strong cold air outbreak from the polar region on 7 April 2001. At the surface, the low (L in Figure 8a) and high-pressure centers $(\mathrm{H}$ in Figure 8a) are located over eastern and western
Mongolia, respectively, on 9 April. In contrast to the U type, the synoptic situation for this case is characterized by an intense surface high $(1047 \mathrm{hPa})$ and a weak surface low $(1011 \mathrm{hPa})$ to the west and east sides of the dust parcel. Dust events are observed across the Taklamakan Desert, Loess Plateau, and Gobi Desert. The traced dust parcel is located over the Gobi Desert, behind the surface front (Figure 8a). Over the same areas, the surface station reports a strong wind of $20 \mathrm{~m} \mathrm{~s}^{-1}$, a temperature of $0^{\circ} \mathrm{C}$ and a very low dew point temperature of $-22^{\circ} \mathrm{C}$.

[44] In the L type trajectory, the initial stage is followed by the downwind transport stage. Figure $8 \mathrm{~b}$ shows the $700 \mathrm{hPa}$ analyses during the downwind transport stage. Note that the dust parcel is located upstream of the trough, where sinking motion prevails. Unlike the U type, the dust parcel in this case remains in the boundary layer during its downwind transport. Figure $8 \mathrm{~b}$ also shows that the dust clouds are widespread over the areas from northern to northwestern China. Later in this stage, the dust clouds move quickly over a rather short distance toward the downwind areas, with dust concentrations reaching $736 \mu \mathrm{g} \mathrm{m}^{-3}$ (Table 2) over the eastern coast, which is much higher compared to the concentration in other cases.

[45] Figure 8c illustrates the east-west vertical cross section of dust concentration and streamlines along $43^{\circ} \mathrm{N}$ (AB line in Figure 8b) at 12 UTC on 9 April. Apparently, the dust clouds are transported in the lower troposphere, from the surface to around $700 \mathrm{hPa}$. The high dust concentration remains within the lower troposphere in southern Mongolia and northern China due to the sinking motion over the areas upstream of the trough. The sloping streamlines in Figure 8c illustrate this sinking motion. A dust cloud descends over the areas from about $300 \mathrm{hPa}$ to the level of the dust parcels. The descending dust clouds are uplifted from ascending areas of the low center located in the northeastern Mongolia $\left(50^{\circ} \mathrm{N}, 115^{\circ} \mathrm{E}\right.$ in Figure $\left.8 \mathrm{~b}\right)$, and then descended southward toward the areas where the dust parcel is located. The two distinct dust levels below and above the dust parcel in Figure 8c also indicate the two different sources of the dust layers.

\subsection{Type: Case 5}

[46] The dust particles of the D type descend from altitudes much higher than $700 \mathrm{hPa}$ after their generation. Case 5 is a typical case of this type and is therefore selected for discussion.

[47] The dust parcel in the backward trajectory of Case 5 is located over the southern Gobi Desert in northern China where the dust observations are also reported at 0600 UTC on April 13. The location of the traced dust parcel is far behind the surface front and very close to the surface high pressure center. The surface high in Case 5 is not as strong $(\mathrm{H}=1031 \mathrm{hPa})$ as in the $\mathrm{L}$ type. The surface wind in proximity to the dust parcel is around $5 \mathrm{~m} \mathrm{~s}^{-1}$, with a temperature of $7^{\circ} \mathrm{C}$ and dew point temperature of $-8^{\circ} \mathrm{C}$, indicating local dry conditions during the initial stage.

[48] During the ascending stage, the dust parcel with the surrounding dust clouds are uplifted to the downstream of a short-wave trough at $400 \mathrm{hPa}$ (Figure 9b). A ascending motion prevails due to positive vorticity advection associated with this short-wave trough, although the motion is already 

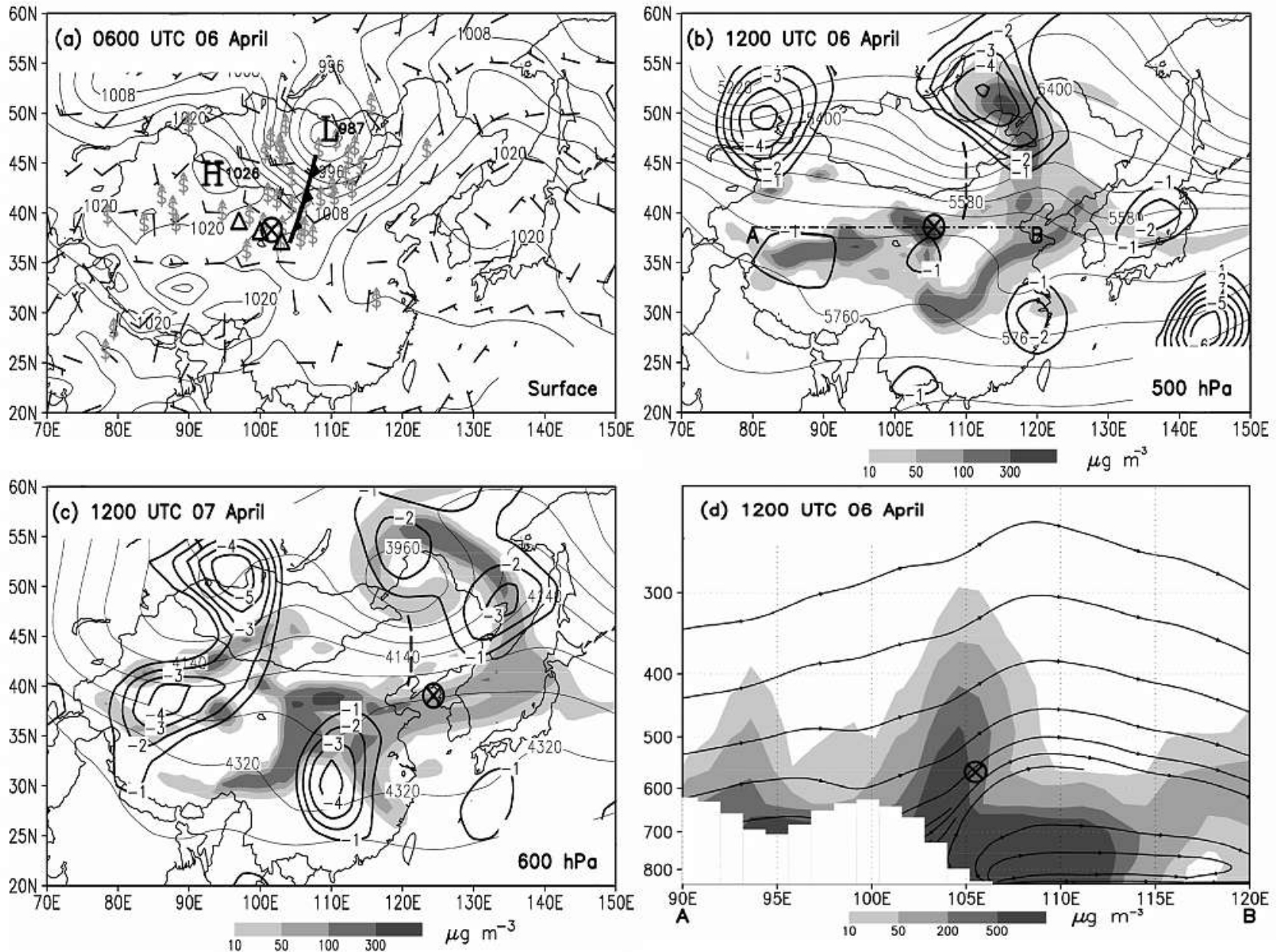

Figure 7. Synoptic maps of Case $1 \mathrm{~b}$ (U type). (a) Surface analyses before the initial stage at 0600 UTC 6 April 2001; (b) $500 \mathrm{hPa}$ analyses during the ascending stage at $1200 \mathrm{UTC} 6$ April 2001; (c) $600 \mathrm{hPa}$ analyses during the downwind transport stage at 1200 UTC 7 April 2001. Vertical cross-section of dust concentration, the streamline along $\mathrm{AB}\left(38.6^{\circ} \mathrm{N}\right.$, dash dot line), and terrain (blank areas near surface) in panel (b) at 1200 UTC 6 April is illustrated in (d). At the surface level, isobars are analyzed at 4-hPa intervals. The full barb and half barb represent 10 and $5 \mathrm{~m} \mathrm{~s}^{-1}$, respectively. Dust observations (dollar sign) and the locations of dust parcels identified by trajectory analyses (circle with cross inside) are plotted. Mountain Qilian is marked by open triangles. Geopotential heights (gpm, light solid lines) are analyzed at 60-gpm intervals and upward motions (heavy solid lines) are analyzed at $10 \mathrm{~Pa} \mathrm{~s}^{-1}$ intervals at both 500 and $600 \mathrm{hPa}$. Shaded areas indicate the calculated dust concentration $\left(\mu \mathrm{g} \mathrm{m}^{-3}\right)$. Surface front (line with solid triangle) and upper-level trough (heavy dash line) are plotted.

weak at this $400 \mathrm{hPa}$ level. After the dust parcel ascend to slightly higher than $400 \mathrm{hPa}$, it begins to descend (Figure 6).

[49] During the downwind transport stage, the traced dust parcel descend quickly to $700 \mathrm{hPa}$ over the area upstream of the trough (Figure 9c). The trajectory of this case also shows that the traced dust parcel descends toward the eastern coast of the continent later in this stage (Figure 6). On April 18, a dust concentration of $245 \mu \mathrm{g} \mathrm{m}^{-3}$ (Table 2) is measured off the eastern coast of China. Compared with the dust parcel in the $U$ type, the traced dust parcel in the D type is located in the descending region behind a trough, rather than to the south or ahead of the trough, during the downwind transport stage.

[50] Figure 9d shows the east-west vertical profile of dust concentration and streamlines along $39^{\circ} \mathrm{N}$ where the traced dust parcel is located at 1200 UTC on April 13 (AB line in Figure $9 \mathrm{~b}$ ). It shows that the dust parcel is lifted to about $450 \mathrm{hPa}$, while the surrounding dust clouds reach as high as $400 \mathrm{hPa}$ within the downstream areas of the shortwave trough. The streamlines also indicate the ascending motion over the area of the traced dust parcels. The areas to the east of the uplifted dust clouds are located upstream of the major trough (heavy dash line near B in Figure 9b), and thus the dust clouds mainly remain near the surface due to descending motion (Figure 9d).

\section{Discussion}

[51] Through the trajectory analyses, different dust sources for the U, L and D types are found (Figure 1). For the U 

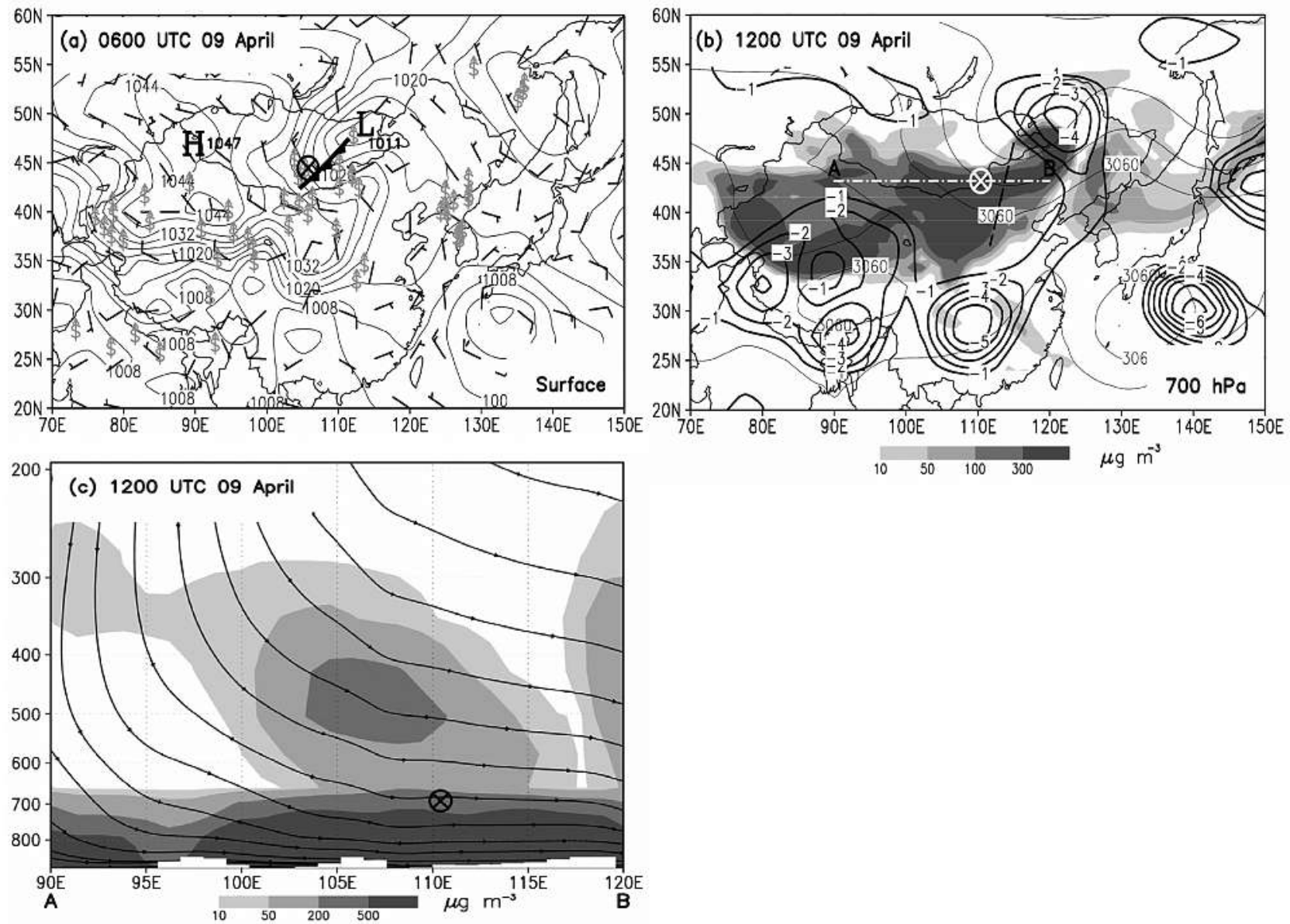

Figure 8. As in Figure 7, but for Case 2b (L type). (a) Surface analyses before the initial stage at 0600 UTC 9 April 2001; (b) $700 \mathrm{hPa}$ analyses during downwind transport stage at 1200 UTC 9 April. Vertical cross-section along $\mathrm{AB}\left(43.2^{\circ} \mathrm{N}\right)$ in panel (b) at 1200 UTC 9 April is illustrated in (c).

and D types, southern Mongolia (Case 2a in U type), Inner Mongolia in northern China (Cases $1 \mathrm{~b}$ and 8 in $U$ type; Cases $4 \mathrm{~b}$ and 5 in D type), Loess Plateau (Case $4 \mathrm{a}$ in D type), and the deserts in western China (Case 1a in D type) are the sources, while for the L type, the Gobi Desert (Cases $2 \mathrm{~b}$ and 3) and Northeast China (Cases 6 and 7) are the sources. The source areas for the three trajectory types can be in any of China's deserts, although it is likely that the areas in the $L$ type are to the north of the $U$ and $D$ types. Similar results to that of the L type were found in a previous study by Sun et al. [2001]. In that study, the dust originating from the Gobi Desert was mostly transported through the lower troposphere below $3 \mathrm{~km}$.

[52] The dust transport is classified into upper-level, lower-level, and descending types in this study. However, during a dust event, more than one transport type can occur. For example, both upper-level (Case 2a) and lower-level (Case 2b) transport types are observed in the dust event occurring on 11 April 2001. The transport type of a dust event strongly depends on the source areas relative to the synoptic conditions. If the source areas are under the influence of both the upstream and downstream sides of a tough, then multiple transport types of dust are possible.
[53] Synoptic conditions for different transport types are summarized in Figure 10. Figure 10a shows that, in the $\mathrm{U}$ type, the surface low $(\mathrm{L}=987-998 \mathrm{hPa})$ is more intense than in the $\mathrm{L}$ types $(\mathrm{L}=1000-1011 \mathrm{hPa})$. The dust particles of this type are also generated nearby the surface front under the area of cyclonic circulation associated with low center. During the ascending stage, the dust particles in the U type are uplifted slightly to the south of the trough or far ahead of the trough. The trough system, with associated vorticity advection and temperature advection, supports the ascent of dust particles ahead of the trough. Other processes, such as terrain effects, can also promote the rising motion, as discussed previously, and are important for the high-level transport of dust particles. Thus the dust particles in most of the U type cases are lifted upward by a trough and through additional mechanisms. During the downwind transport stage, the dust particles of the $U$ type move to the southeast or ahead of the trough system. Thus before descending to a lower level, the dust particles are transported downwind with ascending motion again and could remain in the troposphere over a longer time. The vertical motion in Figure 10a shows that the dust particles of this type are lifted from the surface layer and continue to move downwind through the upper-level system. 

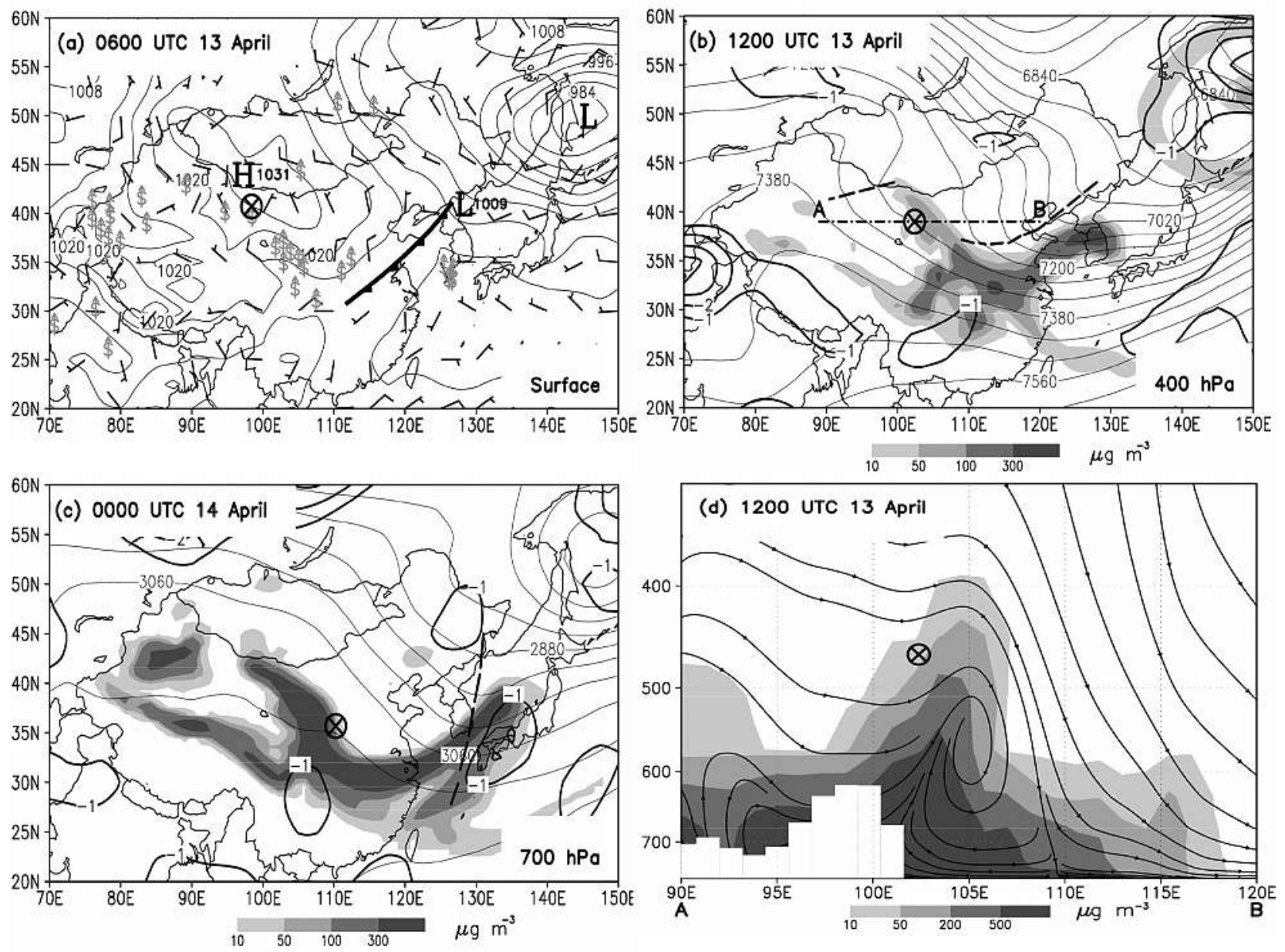

Figure 9. As in Figure 7, but for Case 5 (D type). (a) Surface analyses during the initial stage at 0600 UTC 13 April 2001; (b) $400 \mathrm{hPa}$ analyses during the ascending stage at $1200 \mathrm{UTC} 13 \mathrm{April}$; (c) $700 \mathrm{hPa}$ analyses during downwind transport stage at 0000 UTC 14 April. Vertical cross-section along AB $\left(39.0^{\circ} \mathrm{N}\right)$ in panel (b) at 1200 UTC 13 April is illustrated in (d).

[54] Figure 10b shows that in the L type, the surface high $(\mathrm{H}=1038-1047 \mathrm{hPa})$, and not the low, is mostly more intense than the rest two types $(\mathrm{H}=1024-1034 \mathrm{hPa}$, except one case). The dust particles of this type are generated in between the surface low and high over the area of either cyclonic or anticyclonic circulation. After being generated from surface, the dust particles in L type are located behind the $700 \mathrm{hPa}$ trough, where the rising motion is inhibited. Thus the dust particles move downwind near the surface layer under descending or neutral flow conditions. The vertical motion suggests that the dust particles of the L type are generated in the boundary layer behind the trough and then move downwind near the surface layer.

[55] Figure 10c shows that in the D type, most of the surface low ( $\mathrm{L}=979-995 \mathrm{hPa}$, except one case) is more intense than in the $\mathrm{L}$ types $(\mathrm{L}=1000-1011 \mathrm{hPa})$, similar to the $U$ type, and the dust particles are generated nearby the surface high over the area of anticyclonic circulation. During their ascending stage, the dust particles of the D type are transported upward to areas ahead of the trough. Same as for the $U$ type, the vertical transport of dust particles in the D type during this stage is supported by the ascending motion of the trough or possibly other processes. During the downwind transport stage, the dust particles in the D type move from areas ahead of the trough to areas behind the trough. Since the dust particles in the D type are relatively close to the trough (compare to those in the $U$ type), the different speeds of motion between the trough and the dust particles (for example, dust parcel descends to an area behind the major trough in Case 5) cause the dust particles to fall behind the trough system in this stage. Thus the dust particles in the D type are affected by the sinking motion behind the trough and descend to the lower troposphere. Vertical motion suggests that the dust particles of the D type are first uplifted from the nearby surface high to the downstream regions close to the upper level trough, where ascending motion prevails, but then quickly descend again as dust particles move from the ascending region into the descending region of the trough.

[56] After leaving the source areas, most dust particles in the $U$ type (Cases 1b, 2a, 8) move with limited vertical motion or ascend again due to the trough or some other mechanism so that dust particles can remain in the free troposphere for a longer time. Due to a faster wind speed in the upper levels, their transport distances are also much longer. As discussed previously, Cases $1 \mathrm{~b}$ and $2 \mathrm{a}$ are 

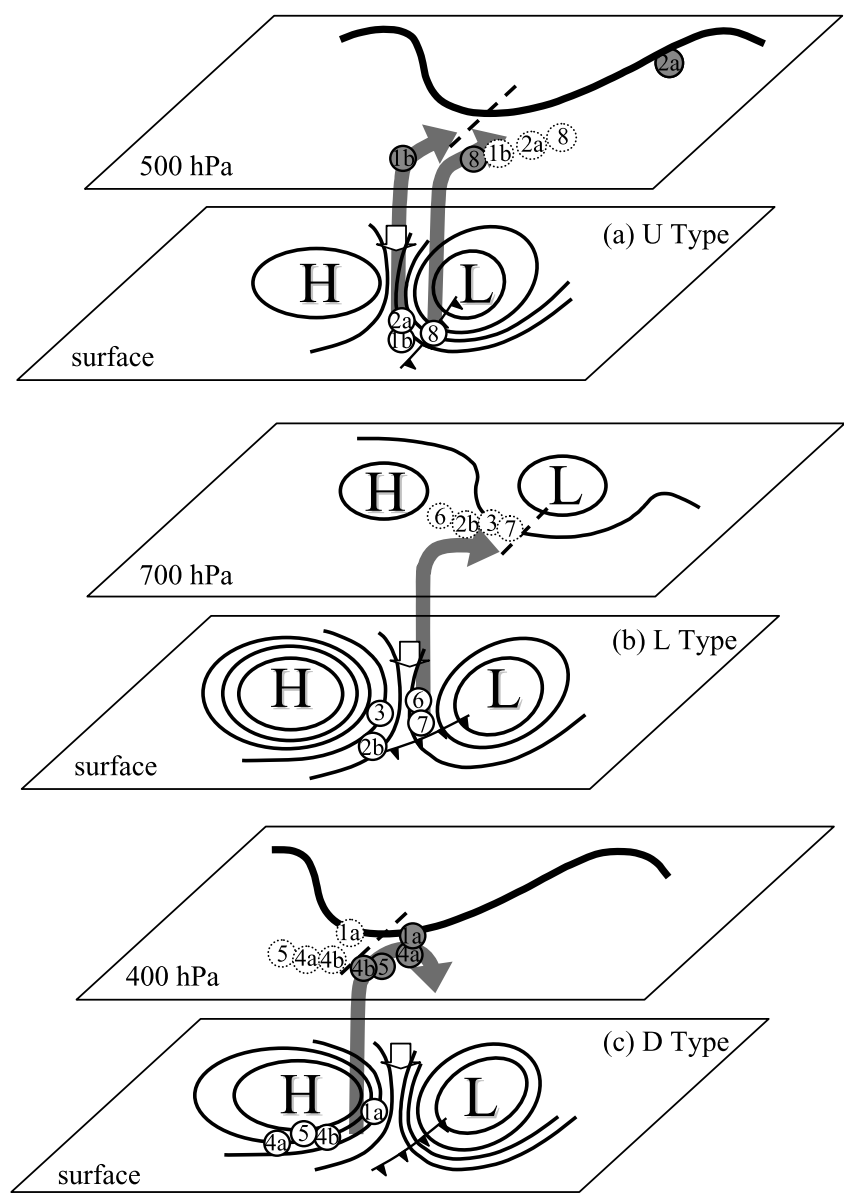

Figure 10. Schematic diagram for the surface and upperlevel systems together with the traced dust parcels, which are transported from the surface to the upper level (grey heavy line with arrow) for the (a) U type, (b) L type, and (c) D type. Circles and case numbers illustrate the locations of the traced dust parcels for different cases during the initial stage (open circles), ascending stage (shaded circles), and downwind transport stage (open dot circles). The locations of trough (dash line) and surface front (solid line with solid triangle) are marked.

characterized by the transport of dust over the Pacific Ocean. For the L (Case 2b, 3, 6, 7) and D type (Cases 1a, $4 \mathrm{a}, 4 \mathrm{~b}, 5)$ trajectories, dust particles descend with time (D type) or travel in the lower troposphere (L type) after leaving their source areas. Therefore their transport distances are also limited to nearby regions. The aircraft measurements only suggest a maximum transport distance off the coast of East Asia for these cases.

[57] The vertical range of dust particles depends on the location of the source region relative to the synoptic patterns during dust initiation as well as the location of the dust particles in the downwind transport stages. In the source areas, a maximum height up to around $350 \mathrm{hPa}$ is suggested by trajectory analyses of the both the $\mathrm{U}$ and $\mathrm{D}$ types. This corresponds to about $7 \mathrm{~km}$ above ground level in the source areas. For most uplifted cases, a maximum height of $400-$ $700 \mathrm{hPa}$ is common. Due to the high topography in dust source areas, this was only around 2 to $4.5 \mathrm{~km}$ above ground level. A similar result was reported by Iwasaka et al. [2003]. In that study, dust layer up to about $6 \mathrm{~km}$ above ground was reported by lidar measurement over the dust source areas. For those ascending dust particles, the height above the ground usually increase right after leaving the source areas due to the ascending motion and lower topography over the downwind areas. In the downwind areas, the observed height is up to $5 \mathrm{~km}$ off the coast of East Asia for these cases, even though the dust particles sometimes descend in the pressure coordinates in the later stage. On the other hand, for dust originated in an area where sinking motion prevails, the dust particles are transported below about $700 \mathrm{hPa}$ above the ground.

\section{Conclusions}

[58] Backward trajectory calculations, synoptic analyses and regional dust simulations are applied to study the mechanisms for regulating Asian dust transport. The aircraft measurements obtained from eight research flights of the NCAR C-130 during the 2001 ACE-Asia experiments are selected for this study. During these flights, aerosol particles with concentrations greater than $100 \mu \mathrm{g} \mathrm{m}^{-3}$ observed both in the free troposphere and near the surface layer are traced back to their source areas, and the result of 11 different trajectories are summarized into three types, including upper level (U type), lower level (L type) and descending (D type) transports. The upper-level transport of dust is observed in the free troposphere above $700 \mathrm{hPa}$, while the lower-level transport is observed below $700 \mathrm{hPa}$ above surface. The pattern of descending types differs between the upper-level and lower-level types, as the trajectories show that the dust particles are uplifted first and then quickly descend to the lower troposphere below around $700 \mathrm{hPa}$. The synoptic conditions are analyzed during different stages of dust transport, including the initial, ascending, and downwind transport stages for the different trajectory types. The mechanisms for the vertical transport of dust and resulting in different downwind distances are found.

[59] The results show that the transport type of the dust events during ACE-Asia in spring 2001 strongly depends on the source areas relative to the synoptic conditions. If the source areas are positioned downstream of a tough, and the system's associated vorticity advection or temperature advection provides upward motion for the dust particles, then the dust particles can be uplifted into the free troposphere. A maximum height of $400-700 \mathrm{hPa}$ is often found for the uplifted particles in the source areas. For dust particles to be transported over long distances, they have to remain in the free troposphere at a relatively high altitude. The relative location of dust particles to the trough system at this stage is also important in determining their altitudes. If the dust particles moved across the ascending areas of a trough, or ascend due to other processes, then they would likely travel over longer distances (U type trajectories). If dust particles are uplifted in an area close to the trough system and are affected by the descending motion of the trough during the later stage, then the particles will descend (D type trajectories) and the transport distance will be limited. Other processes, such as terrain effects, are also important in 
providing the upward motion for the vertical transport of dust.

[60] In contrast, if the sources regions are positioned behind a trough, the vertical lift of dust particles is limited due to the descending motion of the system. Thus the dust particles remain in the lower troposphere below around $700 \mathrm{hPa}$ and the transport distance is much shorter. For any dust event, multiple transport types of dust are possible if the source areas are influenced by the vertical motion of both the upstream and downstream sides of the tough.

[61] This study also found that the synoptic condition is different for the three types of dust transport during dust generation, although strong winds and dry air at the surface are the necessary conditions. Synoptic analyses suggest that strong surface winds are usually associated with the approach of a cyclone and/or the passage of a cold front during the dust generation. The threshold wind velocity appears to be lower $\left(5-13 \mathrm{~m} \mathrm{~s}^{-1}\right)$ in the uplifted types (U and D types) for dust generation over western China, Inner Mongolia in northern China and Loess Plateau, and higher in the lower level type (L type) $\left(13-20 \mathrm{~m} \mathrm{~s}^{-1}\right)$ over the Gobi Desert and Northeast China. This different threshold wind velocity could be due to the various erosion conditions among deserts. In addition, the surface low are mostly more intense in the uplifted cases, including $U$ and D types, while the surface high are mostly more intense in the L type. The dust particles are generated near the surface front under cyclonic circulation associated with the low center in the U type, between the surface low and high pressure systems under either cyclonic or anticylonic circulation in the L type, and close to the surface high pressure system under anticylonic circulation in the D type.

[62] Acknowledgments. Thanks to the NOAA HYSPLIT group for proving the trajectory model on the Website for public use. This research was partially supported by NSC-96-2111-M-002-010-MY3.

\section{References}

Anderson, T., S. J. Masonis, D. S. Covert, N. Ahlquist, S. Howell, A. D Clarke, and C. McNaughton (2003), Variability of aerosol optical properties derived from in situ aircraft measurements during ACE-Asia, J. Geophys. Res., 108(D23), 8647, doi:10.1029/2002JD003247.

Andreae, T. W., M. O. Andreae, C. Ichoku, A. Karnieli, L. Orlovsky, W. Maenhaut, and J. Cafmeyer (2002), Light scattering by dust and anthropogenic aerosol at a remote site in the Negev desert, Israel, J. Geophys. Res., 107(D1), 4008, doi:10.1029/2001JD900252.

Aoki, I., Y. Kurosaki, R. Osada, T. Sato, and F. Kimura (2005), Dust storms generated by mesoscale cold fronts in the Tarim Basin, Northwest China, Geophys. Res. Lett., 32, L06807, doi:10.1029/2004GL021776.

Arimoto, R., X. Y. Zhang, B. J. Huebert, C. H. Kang, D. L. Savoie, J. M. Prospero, S. K. Sage, C. A. Schloesslin, H. M. Khaing, and S. N. Oh (2004), Chemical composition of atmospheric aerosols from Zhenbeitai, China, and Gosan, South Korea, during ACE-Asia, J. Geophys. Res., 109, D19S04, doi:10.1029/2003JD004323.

Bodhaine, B. A. (1995), Aerosol absorption measurements at Barrow, Mauna Loa, and the South Pole, J. Geophys. Res., 100, 8967-8975.

Bott, A. (1989), A positive definite advection scheme obtained by nonlinear renormalization of the advective fluxes, Mon. Weather Rev., 117, 10061015 .

Carrico, C. M., P. Kus, M. J. Rood, P. K. Quinn, and T. S. Bates (2003), Mixtures of pollution, dust, sea salt, and volcanic aerosol during ACEAsia: Radiative properties as a function of relative humidity, J. Geophys. Res., 108(D23), 8650, doi:10.1029/2003JD003405.

Chen, G. T.-J., and H.-J. Chen (1987), Study on large-scale features of duststorm systems in East Asia, Meteor. Res., 10(1), 57-79.

Chun, Y., K.-O. Boo, J. Kim, S.-U. Park, and M. Lee (2001), Synopsis, transport, and physical characteristics of Asian dust in Korea, J. Geophys. Res., 106, 18,461-18,469.
Derber, J. C., D. F. Parrish, and S. J. Lord (1991), The new global operational analysis system at the National Meteorological Center, Weather Forecast., 6, 538-547.

Dickerson, R. R., et al. (2007), Aircraft observations of dust and pollutants over northeast China: Insight into the meteorological mechanisms of transport, J. Geophys. Res., 112, D24S90, doi:10.1029/2007JD008999.

Draxler, R. R., and G. D. Hess (1997), Description of the HYSPLIT 4 modeling system, NOAA Tech. Memo. ERL ARL-224, 24 pp.

Duce, R. A., C. K. Unni, B. J. Ray, J. M. Prospero, and J. T. Merrill (1980), Long-range transport of soil dust from Asia to the tropical North Pacific: Temporal variability, Science, 209, 1522-1524.

Fan, S., L. W. Horowitz, H. Levy II, and W. J. Moxim (2004), Impact of air pollution on wet deposition of mineral dust aerosols, Geophys. Res. Lett., 31, L02104, doi:10.1029/2003GL018501.

Fuelberg, H. E., R. O. Loring Jr., M. V. Watson, M. C. Sinha, K. E. Pickering, A. M. Thompson, G. W. Sachse, D. R. Blake, and M. R. Schoeberl (1996), TRACE A trajectory intercomparison: 2. Isentropic and kinematic methods, J. Geophys. Res., 103, 23,927-23,939.

Grell, G. A., J. Dudhia, and D. R. Stauffer (1995), A Description of the Fifth-Generation Penn State/NCAR Mesoscale Model (MM5), Mesoscale and Microscale Meterorological Division, NCAR Technical Note, NCAR/TN-398+STR.

Hannan, J. R., H. E. Fuelberg, J. H. Crawford, G. W. Sachse, and D. R. Blake (2003), Role of wave cyclones in transporting boundary layer air to the free troposphere during the spring 2001 NASA/TRACE-P experiment, J. Geophys. Res., 108(D20), 8785, doi:10.1029/2002JD003105.

Huebert, B. J., T. Bates, P. B. Russell, G. Shi, Y. J. Kim, K. Kawamura, G. Carmichael, and T. Nakajima (2003), An overview of ACE-Asia: Strategies for quantifying the relationships between Asian aerosols and their climatic impacts, J. Geophys. Res., 108(D23), 8633, doi:10.1029/ 2003JD003550.

Husar, R. B., J. M. Prospero, and L. L. Stowe (1997), Characterization of tropospheric aerosols over the oceans with NOAA advanced very high resolution radiometer optical thickness operational product, J. Geophys. Res., 102, 16,889-16,909.

Husar, R. B., et al. (2001), Asian dust events of April 1998, J. Geophys. Res., 106, 18,317-18,330.

Iwasaka, Y., H. Minoura, and K. Nagaya (1983), The transport and special scale of Asian dust-storm clouds: A case study of the dust-storm event of April 1979, Tellus, 35B, 189-196.

Iwasaka, Y., et al. (2003), Large depolarization ratio of tropospheric aerosols over the Taklamakan Desert revealed by lidar measurements: Possible diffusion and transport of dust particles, J. Geophys. Res., 108(D23), 8652, doi:10.1029/2002JD003267.

Jeng, F.-T., J. S. Chang, K.-H. Chang, H. Huang, and T. Liu (2000), Taiwan air quality model user manual (in Chinese), Graduate Institute of Environmental Engineering, National Taiwan University, Taipei, Taiwan.

Kalnay, E., et al. (1996), The NCEP/NCAR 40-year reanalysis project, Bull. Am. Meteorol. Soc., 77, 437-471.

Kanamitsu, M. (1989), Description of the NMC global data assimilation and forecast system, Weather Forecast., 4, 335-342.

Kim, K. W., Z. He, and Y. J. Kim (2004), Physicochemical characteristics and radiative properties of Asian dust particles observed at Kwangju, Korea, during the 2001 ACE-Asia intensive observation period, J. Geophys. Res., 109, D19S02, doi:10.1029/2003JD003693.

Kistler, R., et al. (2001), The NCEP-NCAR 50-year reanalysis: Monthly means CD-ROM and documentation, Bull. Am. Meteorol. Soc., 82, 247267.

Kurosaki, Y., and M. Mikami (2003), Recent frequent dust events and their relation to surface wind in east Asia, Geophys. Res. Lett., 30(14), 1736, doi:10.1029/2003GL017261.

Lim, J.-Y., and Y. Chun (2006), The characteristics of Asian dust events in Northeast Asia during the springtime from 1993 to 2004, Global Planet. Change, 52, 231-247.

Liu, M., D. L. Wesphal, S. Wang, A. Shimizu, N. Sugimoto, J. Zhou, and Y. Chen (2003), A high-resolution numerical study of the Asian dust storms of April 2001, J. Geophys. Res., 108(D23), 8653, doi:10.1029/ 2002JD003178.

Masonis, S. J., K. Franke, A. Ansmann, D. Müller, D. Althausen, J. A. Ogren, A. Jefferson, and P. J. Sheridan (2002), An intercomparison of aerosol light extinction and $180^{\circ}$ backscatter as derived using in situ instruments and Raman lidar during the INDOEX field campaign, J. Geophys. Res., 107(D19), 8014, doi:10.1029/2000JD000035.

Matsuki, A., et al. (2003), Seasonal dependence of the long-range transport and vertical distribution of tropospheric aerosols over east Asia: On the basis of aircraft and lidar measurements and isentropic trajectory analysis, J. Geophys. Res., 108(D23), 8663, doi:10.1029/2002JD003266.

McKendry, I. G., J. P. Hacker, R. Stull, S. Sakiyama, D. Mignacce, and K. Reid (2001), Long-range transport of Asian dust to the lower Fraser 
Valley, British Columbia, Canada, J. Geophys. Res., 106(D16), 18,36118,370 .

Merrill, J. T., and J. Kim (2004), Meteorological events and transport patterns in ACE-Asia, J. Geophys. Res., 109, D19S18, doi:10.1029/ 2003JD004124.

Merrill, J. T., M. Uematsu, and R. Bleck (1989), Meteorological analysis of long range transport of mineral aerosols over the North Pacific, J. Geophys. Res., 94(D6), 8584-8598.

Murayama, T., et al. (2003), An intercomparison of lidar-derived aerosol optical properties with airborne measurements near Tokyo during ACEAsia, J. Geophys. Res., 108(D23), 8651, doi:10.1029/2002JD003259.

Natsagdorj, L., D. Jugder, and Y. S. Chung (2003), Analysis of dust storms observed in Mongolia during 1937-1999, Atmos. Environ., 37, 14011411

Park, M. H., Y. P. Kim, C.-H. Kang, and S.-G. Shim (2004), Aerosol composition change between 1992 and 2002 at Gosan, Korea, J. Geophys. Res., 109, D19S13, doi:10.1029/2003JD004110.

Parrish, D. F., and J. C. Derber (1992), The National Meteorological Center's spectral statistical interpolation analysis system, Mon. Weather Rev., 120, 1747-1766

Perry, K. D., S. S. Cliff, and M. P. Jimenez-Cruz (2004), Evidence for hygroscopic mineral dust particles from the Intercontinental Transport and Chemical Transformation Experiment, J. Geophys. Res., 109, D23S28, doi:10.1029/2004JD004979.

Petersen, R. A., and J. D. Stackpole (1989), Overview of the NMC production suite, Weather Forecast., 4, 313-322.

Pleim, J., and J. S. Chang (1992), A non-local closure model for vertical mixing in the convective boundary layer, Atmos. Environ., 26, 965-981.

Pruppacher, H. R., and J. D. Klett (1978), Microphysics of Cloud and Precipitation, pp. 714-724, D. Reidel, Norwell, Mass.

Rex, R. W., J. K. Syers, M. L. Jackson, and R. N. Clayton (1969), Eolian origin of quartz in soils of Hawaiian Islands and Pacific pelagic sediments, Science, 163, 277-291.

Shaw, G. E. (1980), Transport of Asian desert aerosol to the Hawaiian Islands, J. Appl. Meteorol., 19, 1254-1259.

Shimizu, A., N. Sugimoto, I. Matsui, K. Arao, I. Uno, T. Murayama N. Kagawa, K. Aoki, A. Uchiyama, and A. Yamazaki (2004), Continuous observations of Asian dust and other aerosols by polarization lidars in China and Japan during ACE-Asia, J. Geophys. Res., 109, D19S17, doi:10.1029/2002JD003253.

Stohl, A. (1998), Computation, accuracy and applications of trajectories - a review and bibliography, Atmos. Environ., 32, 947-966.

Sun, J., M. Zhang, and T. Liu (2001), Spatial and temporal characteristics of dust storms in China and its surrounding regions, 1960-1999: Relations to sources area and climate, J. Geophys. Res., 106, 10,325-10,333.
Takemi, T., and N. Seino (2005), Dust storms and cyclone tracks over the arid regions in east Asia in spring, J. Geophys. Res., 110, D18S11, doi:10.1029/2004JD004698.

Trochkine, D., Y. Iwasaka, A. Matsuki, M. Yamada, Y-S. Kim, T. Nagatani, D. Zhang, G.-Y. Shi, and Z. Shen (2003), Mineral aerosol particles collected in Dunhuang, China, and their comparison with chemically modified particles collected over Japan, J. Geophys. Res., 108(D23), 8642 , doi:10.1029/2002JD003268

Tsai, F., T.-H. Liu, S. C. Liu, T.-Y. Chen, T. L. Anderson, and S. J. Masonis (2004), Model simulation and analysis of coarse and fine particle distributions during ACE-Asia, J. Geophys. Res., 109, D19S20, doi:10.1029/ 2003JD003665

Uematsu, M., R. D. Duce, J. M. Prospero, L. Chen, J. T. Merrill, and R. L. McDonald (1983), Transport of mineral aerosol from Asia over the North Pacific Ocean, J. Geophys. Res., 88, 5343-5352.

Wang, W., and Z. Fang (2006), Numerical simulation and synoptic analysis of dust emission and transport in East Asia, Global Planet. Change, 52, $57-70$.

Wang, Z., H. Ueda, and M. Huang (2000), A deflation module for use in modeling long-range transport of yellow sand over east Asia, J. Geophys. Res., 105, 26,947-26,959.

Wang, X., Y. Ma, H. Chen, G. Wen, S. Chen, Z. Tao, and Y. S. Chung (2003), The relation between sandstorms and strong winds in Xinjiang, China, Water Air Soil Pollut., 3, 67-79.

Wilkening, K. E., L. A. Barrie, and M. Engle (2000), Trans-Pacific air pollution, Science, 290, 65-66.

Xiao, H., G. R. Carmichael, and J. Durchenwald (1997), Long-range transport of SOx and dust in East Asia during the PEM B experiment, J. Geophys. Res., 102, 28,589-28,612.

Zhou, J., G. Yu, C. Jin, F. Qi, D. Liu, H. Hu, Z. Gong, G. Shi, T. Nakajima, and T. Takamura (2002), Lidar observations of Asian dust over Hefei, China, in spring 2000, J. Geophys. Res., 107(D15), 4252, doi:10.1029/ 2001JD000802.

G. T.-J. Chen, Department of Atmospheric Sciences, National Taiwan University, No. 1, Sec. 4, Roosevelt Road, Taipei 106, Taiwan. (george@ george2.as.ntu.edu.tw)

W.-D. Lin and T.-H. Liu, Department of Atmospheric Sciences, National Central University, No. 300, Jung-da Road, Jhung-li 320, Taiwan. (s0641004@cc.ncu.edu.tw; tliu@ncu.edu.tw)

F. Tsai, Department of Marine Environmental Informatics, National Taiwan Ocean University, No. 2, Pei-Ning Road, Keelung 20224, Taiwan. (fujung@mail.ntou.edu.tw)

J.-Y. Tu, Department of Atmospheric Sciences, Chinese Culture University, 55, Hwa-Kang Road, Yang-Ming-Shan, Taipei 11114, Taiwan. (tjy@staff.pccu.edu.tw) 